Postprint of

“Dancing horses and reflecting humans”. Choreographic Practices, 5:2 (2015), 241-257

\title{
Dancing horses and reflecting humans
}

Daniel Meyer-Dinkgräfe, University of Lincoln

\begin{abstract}
In October 2012, German dancer and philosopher Aurelia Baumgartner presented her 90minute production Tanzende Pferde: Spiegelungen im Raum/Dancing Horses: Reflections in Space. Set in an arena, with a raised stage and a projection screen in the background, it provided a performed anthology of the relationship between human and horse. In the article, Meyer-Dinkgräfe discusses the production based on viewing a 40-minute DVD edited by Baumgartner from footage from two cameras recorded during the two 90minute performances. The author's testimony is complemented by Baumgartner's comments and the context of critical literature exploring the relation of performance and animals that has emerged over the past fifteen to twenty years.
\end{abstract}

\section{Keywords}

performance

dance

animals

philosophy

adaptation

choreography 


\section{Introduction}

In October 2012, German dancer and philosopher Aurelia Baumgartner presented two performances of her 90-minute production Tanzende Pferde: Spiegelungen im Raum/Dancing Horses: Reflections in Space in an arena, with a raised stage and a projection screen in the background. The production set out to show a performed anthology of the relationship between human and horse. The scope of that anthology was provided by ten distinct scenes, each with its specific contents, performers, presentation style and title. In the resulting panorama of impressions, unity was provided by the performance space and the ever-present combination of projected film and live presence of humans and horses.

\section{TS: INSERT FIGURE 1}

Figure 1: Dancing Horses: Reflections in Space. Photo: Aurelia Baumgartner, edited by Roman Lyuken.

The article about this work of art is based on a specific perspective on it: MeyerDinkgräfe’s viewing of a 40-minute DVD edited by Baumgartner, based on footage from two cameras recorded during the two 90-minute performances. This particular perspective, a video of a choreography created by the original choreographer, was available for viewing as often as desired, in comparison with a performance that is much more short-lived and in that sense unique. The article focuses predominantly on the visual impression, leaving a discussion of the live music provided by bass, guitar and trombone 
to a separate discussion. The aim of the article is to provide a useful, honest and to the point testimony of this particular piece, and to add analytic force by contextualizing the insights gained from that predominantly descriptive testimony. The contexts are on the one hand the choreographer's perspective on selected aspects and scenes of the production, and on the other hand the critical literature exploring the relation of performance and animals that has emerged over the past fifteen to twenty years. A comparison of this production with other productions, past and present, that have used horses onstage (e.g., Joanna Haigood's Equus Project; see also Poppiti (2005) and Shook (2008)) is beyond the scope of this article.

\section{Meyer-Dinkgräfe: Descriptive testimony}

Scene one of Tanzende Pferde: Spiegelungen im Raum/Dancing Horses: Reflections in Space encompasses a wide range of the horse-human interactions covered by, and the range of modes of presentation characteristic of the production: we become aware of the performance areas: the arena, the stage and the screen. The performers become visible: horses and humans, in the shade, in brighter light, in silhouettes from behind the screen, sometimes lit to appear as centaurs, half human, half horse, blurring boundaries - an effect enhanced by the blurring of projected images of buildings and structures, examples of built environment, human-created architecture, giving way to a red-lit area with sparkling fireworks in the background. The title of the scene is 'Traumwelt'/'Dream World', in which everything is possible. 
The first scene does not only provide the framework of contents and range of visual contexts, but also demonstrates and at the same time questions the status quo of horsehuman interaction - two humans lead their horses through the arena, representing perhaps the most common association between horse and human, the human as guide and the horse as obediently following the human guide. This has been, for millennia, a relationship that has been widely accepted and not much questioned in ethical terms. Only after a few moments of the performance are the two humans guiding the horses revealed as female, however. This casting challenges the assumed status quo, insofar as at least historically; it may well have been men who are more closely associated with animals than women.

It is striking to note that the production ends with the status quo in its more expected form, insofar as in scene ten, which makes use of the entire arena area, it is two men who are guiding two work horses around performing various chores, pulling, for example, a log behind them on a harness, or pulling a sheet of cloth. At the end of the scene and with it the performance, the two men and their horses are joined by many other performers dressed as peasants: male and female, adults and children. However, this last scene comes after we have watched the eight scenes in between, which have at least sought to develop the questions launched by the choice of having two women lead their horses into the arena in the first scene - hence scene ten is entitled: 'Viele Fragen: Module im Loop’/Many Questions: Modules in a Loop’. 
The eight scenes in between the frame provided by scenes one and ten scenes pulsate as contractions and expansions of the relationship between humans and the horses, combining, separating, and blurring tradition and innovation in the process. They are expressions of Baumgartner's aim to investigate through her practice, through the performance, the question of whether it is possible that horse and human communicate through dance and whether it is thus possible that they find a common language of movement through what can be defined as free artistic play.

Scene two expands the relationship of female guide and their horses from the general context of scene one to a more playful, colourful dimension: six German women dressed in Arab garments walk in, their movement stylized and ceremonial. They walk in pairs, hand in hand, in a row. Two horses are led in behind them, one by a woman, the other possibly by a man. Both those humans also move in rhythm to the music. The background image changes colour to silver, with a central light source emanating sparkles, which is reminiscent of Peter Brook's film version of the Mahabharata, when Kunti invokes the gods to create her children. The movement of the women on the arena floor gets more lively and rhythmical, while the horses are being led faster as well. Then the women begin to engage in dance movements, presumably of the style relating to the garments they are wearing. Their movement is feminine, circular, free flowing, free moving and engaging. Earth, the red floor of the arena, is the ground, the basis, the provider, the source, and the security of humans and animals, of their lives, their bodies, their ambitions, their abilities, their play and playfulness, and their expression in colours, in music and in rhythm. The scene is entitled 'Die Erde lebt'/‘Earth Lives'. This part of 
the scene relates to expansion, encompassing a wide range, freedom and community. The scenario narrows and contracts to reveal one female solo dancer performing a dance with a large veil, which she holds in both hands and moves in elegant waves around her body. Another woman, meanwhile, leads a horse in the background. It is not clear whether the horse in the background with the woman guiding that horse are projections or really in the space.

Scenes three and five work with projections of text on to the screen - these are further examples of the exploration of performative interrogation of established roles and assumptions, raising, for example, the question of whether the working horse might be in fact superior to their human guides. Baumgartner adapted the text from Swift's Gulliver's Travels (1726) and Kafka’s Ein Bericht für eine Akademie / A Report for an Academy. In scene three, entitled 'Auf der Suche’/'In Search Of', a horse with a load on its back (signifying the horse's assumed inferiority) is led in by one person who also carries a small lantern that creates intriguing light effects, immediately followed by a second horse without load led by two people. The text that accompanies this is translated from German: 'Once Upon a Time / That's how all fairy tales begin / And most of the time they lead us into a forest. / A fairy tale of Yahoos and Houyhnhnms’. The fairy tale scenario is thus evoked by the text, and the relationship between humans as superior and horses as inferior is questioned with reference to the role of humans and horses in Swift's Gulliver's Travels. In the scene 'Wer bist Du'/'Who Are You', this ambiguity of inferiority and superiority is developed further in its juxtaposition of a conventional circus-style dressage and text from Kafka's text, which features a creature who was an 
ape once, who delivers a lecture about his turning into a human. In the scene, Christina Valle presents her Haflinger gelding Stromboli walking around the perimeter of the arena, and walking in different steps. The horse is made to put his front legs up on a platform and to move its legs in the direction of its reigns, then is made to come down to the arena ground again, made to lie down on its side and get up again and walk around the arena.

\section{TS: INSERT FIGURE 2}

Figure 2: Christina Valle presents her Haflinger gelding Stromboli. In the background: projection of text from Kafka’s Reden für eine Akademie/Lectures for an Academy. Photo: Joerk Henkel

Thus, the performance juxtaposes the aesthetic contexts of horses in scene one ('Traumwelt') and scene two ('Die Erde lebt') with more mundane contexts for the existence of horses as working for humans (signified by the load carried by one of the horses) in scene three, and performing for humans (dressage in scene five). At the same time, the binary opposites of human-animal; inferior-superior; master-servant; aesthetic-work; and real life-fairy tale are put into question in terms of the themes or titles of the scenes, 'Dreamworld', 'Earth Lives', 'In Search Of' and 'Who Are You', which hint at the possibility, or at least the aim of unification of binaries, in a more holistic perspective.

The seemingly conventional, but in fact much more ambiguous dressage in scene five was preceded, in scene four, entitled 'Fnarp', by exclusive focus on humans in what 
comes across as reminiscent of much of what is going on in the contemporary performance art/dance scene, with a range of noises made by the performers (one male, one female), onstage and backstage. Some of the movement vocabulary is from classical ballet, but most is from modern dance material on the verge of acrobatics. The scene focuses the attention and concomitant thinking on humans, their sometimes strange, playful, straightforward or twisted interactions that do not need words.

Once the production has exposed the ambiguity in the roles of horses, it takes the spectator into the realm of Spanish flamenco dance in scenes six and seven, entitled 'Cantes Jondos’ and 'Der Rhythmus der Pferde in den Beinen der Menschen’/‘The Rhythm of the Horses in the Legs of the Humans', respectively. In scene six, Baumgartner dances in flamenco style against projections of images from New York Broadway and London West End, with boards on theatres advertising the musicals Wicked and Mamma Mia.

\section{TS: INSERT FIGURE 3}

Figure 3: Flamenco puro dancer Jairo Amaya with shadow of Frisian Filou. Photo: Joerk Henkel.

In relation to the preceding scenes, 'Cantes Jondos' takes us from the all-encompassing first scene ('Traumwelt') via the exotic oriental context of 'Die Erde lebt' and the contraction within it from several women to the focus on one woman, via the launch of the performative interrogation of established roles and assumptions in 'Auf der Suche', via an exploration of human relationships in 'Fnarp', via further expansion of the perspective through further interrogation of the relationship between horses and humans 
in 'Wer bist Du', to the perspective of one person, with an emphasis on the performing body's rhythm on its own.

The link to horses is quickly re-established in scene seven insofar as the performer, Spanish flamenco dancer Jairo Amaya, engages further in flamenco dance, but this time accompanied by impressive shadows of a horse in the background. The bright light from the background into the space, on to the stage, reveals shadows, silhouettes of the horse. From watching the video it is not certain that the horse is actually moving somewhere behind the light and the screen, which is the area behind the stage. Amaya cuts a different figure compared with Baumgartner in the previous piece. The projections in scene six against the filmed background of architectural elements are different from this one, where some material is projected as well, but not as much, but equally monumental in size and always intercut and over-layered by the horse in silhouette. The kind of movements engaged in by Amaya leads to a feel of the whole scene that is different to the previous one. The previous one was more playful and in a way more conventional in the sense of contemporary dance elements combined with the flamenco footwork. The movements of the horse and the movements of Amaya in relation to each other are unpredictable.

Further adjectives that come to mind are powerful and energetic, but at the same time still of a feminine as opposed to a masculine quality. Whereas the previous section was more in line with taking this one is more related to giving.

Scene Eight, entitled 'Menschenkinder - Tierkinder'/‘Human Children - Animal Children', expands the frame to encompass children for the first time in the performance. The screen is lit with light that starts as a small circle which becomes a large circle 
covering the entire backdrop. It changes from circle to oval. The colour that is projected is a lilac rose colour with a bright white circular light in the background. This is for the stage area. In between the light source and the screen, children are seen in silhouette, playing. The arena is lit with several reddish lights and two ponies are being led around by one person each, each an adult. The children then emerge from behind the screen, they are dressed as typical children learning to dance ballet with tutu and relevant dresses, and they are now taking turns, three of them each leading one of the ponies.

\section{TS: INSERT FIGURE 4}

Figure 4: Aurelia Baumgartner with Arab Grey Pegasus, Raphaelea Baumgartner in the background. Photo: Joerk Henkel.

With scene nine, 'Körperbegegnungen’/'Body Encounters’, we come to the focal point of the whole performance and the centre of this article, demonstrating the range of the potential of the relation between horse and human already hinted at in earlier sections, in particular the opening 'Traumwelt' and the third scene, 'Auf der Suche'. ‘Körperbegegnungen’ starts off with a greenish light in the background. On the stage a young female performer with black hair and white outfit dances in a mix of contemporary and ballet styles, while on the arena floor Baumgartner engages in her main performance with the Arab grey Pegasus. This is no longer a circus act as in an earlier scene 'Wer bist Du?', but something quite different and of its own kind. Holding the horse on a more or less long lead, the Baumgartner engages in her own dance. She leads the horse to move with her, and allows the horse to move on its own. The performer is always moving in relation to the movement of the horse, sometimes allowing the horse a little bit of space 
of its own, which it then uses to inspect the floor; then Baumgartner moves fast towards the horse again. The horse notices and reacts to that fast movement, moving backwards but obviously not afraid, but in line with the movement that is coming towards it. It looks different from a horse that is frightened and shies away. There is much physical contact between Baumgartner and the horse, insofar as the dancer moves with her arms and body against the body of the horse. Meanwhile, the female dark-haired dancer is continuing her performance in the background on the stage. Sometimes the movement of the female on the stage and Baumgartner seems synchronized, sometimes less so. Sometimes the movements of the horse and dancer are slow and relaxed, elegant and calm. On other occasions there is more liveliness in there, and on some occasions where the horse and Baumgartner are livelier, the dancer onstage is in a calmer and settled position. As in Baumgartner's earlier scene six without horses, 'Cantes Jondos', her body is predominantly upright and moving around with the horse, moving with the horse, moving against the horse, but it is also on occasion on the floor and enticing the horse also to change its body posture accordingly.

At this point in the article, we bring in the voice of the choreographer, Aurelia Baumgartner, herself, to add her own perspective to the discussion above. She provides the background to and development of her relationship with her horse, Pegasus, including reference to the characteristics that he brings with him as an Arab Grey, his behaviour in general and in rehearsals for the production.

\section{TS: INSERT FIGURE 5}

Figure 5: Aurelia Baumgartner with Arab Grey Pegasus. Photo: Fenny Rosemann. 


\section{Contextualization (1): Baumgartner - the choreographer's perspective}

The processes with the horses began half a year before the performance when I found a suitable stable and held an information evening that presented the idea of the performance. I asked those people who had their horses in that stable which of them might be interested in joining the production. In August 2012 I gave some of the participants parts of the music so that they could get their horses used to the music, but that was not yet the music that was seen in the performance in the end. Only in September did I give Christina her the piece of the music for the circus number in scene five. However, the music was only set in some parts and particularly the length of its duration was not yet fixed. In this case (as far as the length was concerned) the musicians worked alongside with and according to the abilities and indications of the horses. This was also the case during the performance itself. The same was true for the music for the work horses. The ponies had exercised and trained with classical music; all other music was only distributed on the first day of rehearsals of the ten days' worth of rehearsal.

I danced with Pegasus sometimes without music, sometimes with different kinds of music. The music in the performance itself for my scene with Pegasus had not been composed but was improvised apart from the basic rhythm of the Spanish tango, a fourbeat rhythm. However, the length was my choice and decision. Also the dancer on the stage behind me, my daughter, had firmly choreographed parts that could be put together in different ways. In the end I orientated myself in relation to my daughter, when she had come to an end; similarly the musicians orientated themselves with both of us dancers. 
I bought the Arab grey Pegasus when he was three years old. I believe that it is important to work with one's own horse because of the level of trust that will have developed between horse and owner and horse and human, but I could imagine dancing with other horses. I gave him a lot of opportunity to walk and run on his own and freely. Initially I rode him a lot but found that it does not work well with my dancing, as different kinds of muscles of the legs are being tasked in riding a horse and dancing and the two did not go together well. I played a lot with Pegasus and later also with the mare that joined, Mabrouka, a chestnut. I noticed some behaviour especially in Pegasus that made sense when I read Monty Roberts's work on joined-up horsemanship. Within this context it seems likely that Pegasus developed the idea of me as the dominant mare within a herd of horses. For example, when I allow him to run freely he suddenly comes towards me and walks and runs behind and follows me in every step whenever I choose to move.

This is what is evident and essential to our performance together: the horse considers me as the dominant mare and at the same time maintains his freedom in relation to the human being and is not trained in the sense of a circus number. Thus, the movements between horse and human and in particular the horse itself are not conventional in the sense of dressage or movement to rhythm or music, and it is the question then whether the scientific approach may be more along the lines of the kind of interaction between this horse and this owner. Does he regard me as the dominant mare according to the ideas of Monty Roberts, and are some aspects of the horse's behaviour, which come across to me as invitations to play or dance, related to the stallion's patterns of seeking to impress? All 
of this goes beyond conventional drives of food or sex or fear, but becomes a cultural act, a decision to want to engage in this playful dance as that is what the horse wants to do at that moment.

All this applies in the context of the arena. It would be interesting to see how this works in the open field - possibly there the food drive, especially in the case of Pegasus, might prevail. It is interesting to note that different kinds of horses will probably be behaving and acting in different ways in relation to humans. Arabs in particular are very interested in humans, always want to be in contact with them - when they are standing in their boxes they look and see what people are doing. They demand respect from humans, otherwise they will not develop the friendship or will end friendships. They want communication and it seems that they are interested in understanding human language. In many cases the way that people behave with animals is characterized by a high and inappropriate level of presumptuousness as to what one can do with animals and what they are like. I think that especially Arab horses, despite, or possibly because of their very high level of sensitivity, enjoy particularly to communicate with humans and to dance with them. These horses are the only pure-bred race of horse; they go back to the prophet Mohammed. They have lived since early days with the Bedouins in their tents and the foals grow up with the Bedouin children. They have in those cultural contexts the status of a member of the family. This is the same with Pegasus: while he does not live with me and my daughter at our home, he is a wonderful friend. 
During the rehearsal period, Pegasus did not want to be without his mare Mabrouka in the hall and was very agitated without her; therefore, I could not dance with him under those circumstances. Only when Mabrouka was present in the hall, even if only standing in a corner, was he comforted and calm and interested in dancing. He is very dominant with regard to his mare and is the same in the stables where he is normally living. Mabrouka danced during the rehearsals alone with the Egyptian women and was so happy during this process that she entered into the circle with the women on her own and when in the circle lay down and turned over. Again and again she wanted to join the circle of these women and integrate her own activities with theirs.

I started dancing with Pegasus after I started planning for this production, but with some interruptions and periods without dancing because last year from the middle of July to beginning of August I was in New York, and before that I was busy working on a different piece in Halle in Germany. In the middle of August 2012 I had a Flamenco production and after that we danced when we felt like it. It is something that cannot be enforced. If it is very cold in the stables it does not work for either of us, even when Pegasus wants to. On those occasions I only played with the horse, but on many occasions he tried and provoked me to actually dance.

In scene nine of the production, the contact improvisation between me and Pegasus, it is important to note that Pegasus was only initially led in on a lead rope, but after a while, quite early on in the scene, I released this lead and from then on the animal was free in the arena and was allowed to engage in the dance or not as he liked. I only had two riding 
crops to help me guide the horse as my kinds of elongated arms without wanting to hurt him or without wanting to frighten, only to allow me to keep direct body contact through touching him with them when I was further away from him. On one occasion I did, however, frighten him with the riding crop: he galloped away from me but then he returned to the dance by moving in a curve in which I followed him.

The standard movement of an invitation to dance for Pegasus is to come towards me with raised front legs. He then likes it if I run away from him with pirouettes and he then follows me and when I then turn around and move again with my dance movements towards him, he reacts with a high level of attention and when I then turn around him, he turns in tune with that. He likes it when I touch him, and in the sense of contact improvisation, pass my weight onto him. He is very attentive in those situations and speaks with his front legs. He might, for example, lift a leg and then he likes it when I put my arm under his leg and support it, or if I move his leg with my movement. In this way, steps with raised front legs, a kind of Spanish step, Pegasus turns around his own axis and moves in physical contact with me - these are the fundamental patterns of movement in these encounters. Sometimes the mare comes and wants to join; initially Pegasus wanted to shoo her away in order to dance only with me, but sometimes I do not agree to this and now sometimes I try to involve both horses in the dance with me. Sometimes, therefore, I let Pegasus have his will to dance alone with me, or sometimes we dance all three of us. When we dance all three, the mare moves backwards and I move at her side. Pegasus then moves towards the mare as if the two were a pair or I lean against Mabrouka and begin a contact improvisation with her. However, the mare is more sensitive and tender 
than Pegasus and needs a bit more time to feel herself into the situation and into the human movements and this works best when the mare is alone with me. Otherwise she is distracted by her attention that she needs to pay to Pegasus and he then tends to go in between us again to be alone with me.

With Pegasus I feel that he can express fear and love at the same time. For example, on the second day of the performance, at the second performance of the piece, I put a blanket over him in order not to have to completely wash him anymore because it is his highest delight to roll around in mud pits. One of the other performers helped to clean him and Pegasus stood outside with a blanket over and not on a lead, free. The other performer, Christian, pulled the blanket down without loosening the berth around his belly and thus the blanket was stuck around Pegasus's hind legs. Pegasus hates blankets anyway, his adrenalin level was very high and with that fear of having his hind legs not free he could easily have overrun me, but he did not move from the spot, possibly in order not to hurt me. He only neighed and hopped slightly up and down with hind and front legs in order to get rid of the blanket, which we then removed from him. A further example is that accidentally I came across an abscess with a hoof pick that hurt so much that Pegasus promptly wanted to kick against the pain with his hoof but stopped in mid-air as otherwise he would have kicked me in the belly, which would have hurt and injured me severely. This is another example that points to something else, which is that possibly there is an energy exchange of human and animal (and horse in this case) that is based on a mirror effect in the sense that during the performance there was a moment where I did 
not know whether I was a human or horse and I can only assume that Pegasus would have understood or experienced it in a similar way.

\section{Contextualization (2): Dancing horses and reflecting humans}

On the basis of a descriptive testimony (to allow a readership access to the production that did not see it, supported by a few representative images), and the choreographer's own perspective (which adds to the understanding of the production's creation and intention), it is now possible to provide further critical context for the production. There has been much exploration of the context of performance and animals over the past ten to fifteen years, with special issues in Performance Research (2000) and The Drama Review (2007), and most recently the Theatre \& Animals contribution to the Theatre \& series (Orozco 2013). Where does Baumgartner’s production of Tanzende Pferde: Spiegelungen im Raum sit within this context?

The above two sections of this article suggest that both authors have seen the horses that appear in this performance, in particular Pegasus, in terms that are anthropomorphic, attributing human qualities, especially human emotions, to the horse, perceiving behaviour of the horse in terms of human emotions. This is nothing new, as Putnam explains: in 1798, scientists in Paris had music played to two elephants (originally presents from the East India Company to the Dutch, but confiscated by the French in 1796 and transported to Paris) to establish the effect of music on them. The scientists observed what they referred to as ‘curiosity, surprise, and worry’ (Putnam 2007: 156). Writing about training of big cats for the circus, Tait observes that 'An analysis of 
discourse about training big cats [...] reveals that for all their obedience and clever execution of tricks over years, animal wildness is collapsed into an idea of emotional wildness' (2009: 67). While the big cat trainer seeks to show behaviour that allows the cats to trust him or her, the big cats are deemed 'to be emotionally volatile, unpredictable and untrustworthy' in principle, by nature, and 'the trainer cannot trust the wild animal, who might betray a trainer’s affections at any moment’ (2009: 72). Other historical explorations (Poppiti 2005) and analyses of specific performances (Shook 2008; Carlson 2007; Williams 2007; Dombek 2007) provide further examples of this kind. Current consensus in science suggests that from the behaviour of animals we can conclude that they are likely to have positive and negative emotions, but it is impossible for us to know with any certainty how the animals experience those emotions in relation to how we as humans experience them (Mills 2013).

Ethical issues in the relation of humans and animals in a performance context have featured prominently in the literature. Most take extreme human-animal encounters as their focus, in which a human performer subjects an animal directly and intentionally to suffering and even death. Performance artist Rachel Rosenthal, who has worked successfully with animals in many of her performances in ways she considers appropriate, writes:

I hope that artists can display humaneness where perhaps other people can't. If artists don’t, they are doubly guilty. I assume artists to be capable of empathy, compassion, understanding, respect, and intelligent behavior. If they knowingly 
hurt or demean animals, forcing them to "perform" against their nature, that is a punishable sin. (2007: 7)

Marjanic raises the questions of where the motto of freedom or artistic creativity comes into the debate, and how we can justify the pursuit of ethical accountability of artists in their work with animals in view of the daily mass slaughter of animals for other purposes (2010: 78).

In terms of the ethics of Tanzende Pferde: Spiegelungen im Raum, here is Baumgartner's position:

I agree with Mangelsdorf (2013), who is referring to Brandt (2004) that it would be useful to create a 'third language' as an emphatic dialogue based on body language including movement and emotions. The only question is how this dialogue might be held and who will be the leader of this dialogue, so that in this dialogue horses might not mutually be considered again as inferior to humans by acting only out of their instincts, and their tribe and constitution-based attitude. Based on the experience of dancing with Pegasus, I think that horses have the capacity to choose their role. For example, when I was dancing with Pegasus sometimes he came with these carnivorous frontal movements towards me while I was trying to synchronize my movements with him. Then there is the experience I had with him expressing love and fear at the same time. Accidentally I came across an abscess with a hoof pick; it hurt so much that Pegasus promptly wanted to kick against the pain with his hoof, but stopped in mid-air as otherwise he would have kicked me in the belly, which would have hurt and injured me severely. He chose not to hit me, 
maybe thus expressing a direct form of love towards me. He did not 'want' to hurt me, and I add: he did not want to hurt the human he loves. And this can only happen by his capacity to get a distance from his own pain and to put himself in my role as the one who would be hurt by his kick, thus by distancing himself from his own pain as a sort of 'selfreflection' and by compassion towards me as an expression of love on its highest level (not because of sexuality, but through a capacity of feeling with another body).

In my opinion to create this beautiful creative exchange with horses, humans have to get this peripheral view by using other brain parts as described by movement and breathing practices of several oriental practices like Taiji or Yoga. By grounding the body, opening the energy ways and filling all body cells with Prana or Chi, you get into another state of mind and body consciousness caused by a lower tension of the brain cells because of the oxygen provided by constant deep breath. Thus a human-animal encounter may be created by body language, body thinking that is body-based, centred on the body, mind and the soul, holistic, and not limited to only the human kind of 'thinking'. The humananimal encounter may be created by structuring the 'world' in a different way, maybe a new way, shown in the performative act of the dance between the human and the horse. A different relationship of human and animal (horse) may be built up in the way of a respectful, non-authoritarian, affectionate and playful encounter. To conclude, it may be worth considering whether animals might be understood to exist in a zen-consciousness of here and now, and thus do not have a blunt mind but heightened perception, which might bring them closer to the numinous than humans. 


\section{References}

Brandt, Keri (2004), ‘A language of their own. An interactionist approach to humanhorse communication', Society and Animals, 12:4, pp. 299-316.

Carlson, Marvin (2007), “'I am not an animal”. Jan Fabre’s Parrots and Guinea Pigs’, The Drama Review, 51:1, pp. 166-69.

Chaudhuri, Una (2003), 'Animal geographies, zooesis and the space of modern drama', Modern Drama, 46:4, pp. 646-62.

(2007), '(De-) facing the animals, zooesis and performance’, The Drama Review, 51:1, pp. 8-20.

Dombek, Kristin (2007), 'Murder in the theme park: Evangelical animals and the end of the world', The Drama Review, 51:1, pp. 138-53.

Mangelsdorf, Marion (2013), ‘Liebesgeflüster’ zwischen Menschen und Pferden Möglichkeiten und Grenzen speziesüberschreitender Emotionalität’/'Whispers of love' between humans and horses - possibilities and limitations of speciestranscending emotionality’, Tierstudien, 3, n.p.

Marjanic, Suzana (2010), 'The zoo stage as another ethical misfiring: The spectacle of the animal victim in the name of art', Performance Research, 15:2, pp. 74-79. 
Mills, Daniel (2013), conversation with Daniel Meyer-Dinkgräfe and Aurelia Baumgartner, Skype, 29 August.

Orozco, Lourdes (2013), Theatre \& Animals, Basingstoke: Palgrave Macmillan.

Poppiti, Kimberley (2005), ‘Galloping horses: Treadmills and other theatre appliances in hippodramas', Theatre Design and Technology, 41:4, pp. 46-59.

Putnam, Walter (2007), 'Captive audiences, a concert for the elephants in the Jardin Des Plantes', The Drama Review, 51:1, pp. 154-60.

Rosenthal, Rachel (2007), ‘Animals Love Theatre’, The Drama Review, 51:1, pp. 5-7.

Shook, Estelle (2008), 'Making theatre with horses', Canadian Theatre Review, 135, pp. $55-57$.

Tait, Peta (2009), ‘Trained performances of love and cruelty between species’, Performance Research, 14:2, pp. 67-73.

Williams, David (2007), 'Inappropriate/de others or the difficulty of being a dog', The Drama Review, 51:1, pp. 92-118. 


\section{Contributor details}

Daniel Meyer-Dinkgräfe studied English and Philosophy at the Universität Düsseldorf. In 1994 he obtained his Ph.D. from the University of London. From 1994 to 2007, he was Lecturer and Senior Lecturer in the Department of Theatre, Film and Television Studies, University of Wales Aberystwyth. Since October 2007 he has been Professor of Drama at the Lincoln School of Performing Arts, University of Lincoln. He has numerous publications on the topic of Theatre and Consciousness to his credit, and is the founding editor of the peer-reviewed web journal Consciousness, Literature and the Arts and the book series of the same title with Rodopi.

Contact:

Lincoln School of Performing Arts, University of Lincoln, LPAC Building, Brayford Pool, Lincoln LN6 7TS, UK.

E-mail: dmeyerdinkgrafe@lincoln.ac.uk 